\title{
8 \\ Reflections on Hybridity as an Analytical Lens on State Formation: The Case of Solomon Islands
}

\section{Sinclair Dinnen and Matthew Allen}

\section{Introduction}

In this chapter we draw on a case study of rural Solomon Islands to reflect critically on the value of the concept of 'hybridity' in understanding processes of social, economic and political change underway in this small but socially complex archipelagic Pacific island nation. In foregrounding these processes of change, we draw attention in particular to the inherent tension between contemporary understandings of statebuilding, on one hand, and state formation, on the other. ${ }^{1}$ The former, which tend to dominate policy discussions and some areas of academic debate, are often framed in terms of linear, technical and largely ahistorical projects, with a significant focus on the role of international actors. The latter has its antecedents in historical studies of the emergence of the postWestphalian state and generally views state formation as a predominantly organic, contingent and highly contested process. Our analysis of change

1 Allen and Dinnen, 'Solomon Islands in Transition?', 393-394. 
in Solomon Islands adopts a state formation lens and in this chapter we specifically ask what the concept of hybridity might contribute to our understanding of this process.

Hybridity has been used recently in Solomon Islands with reference to the pluralistic social and regulatory environment that prevails at 'local' 2 levels in rural areas, where 'traditional'3 ${ }^{3}$ and state forms of authority overlap and intersect. As an idea, hybridity serves to highlight the myriad interactions between different institutional forms and value systems that cumulatively shape the character of everyday regulation and ordering at these local levels, particularly in terms of dispute resolution and community governance. ${ }^{4}$

While this usage seeks to describe how social regulation actually works for predominantly rural populations living in areas of limited statehood, the concept of hybridity has also attracted growing attention among policy and development actors in recent years with a more instrumental interest in improving service delivery to dispersed populations in parts of the global South, particularly in respect of justice and security provision. ${ }^{5}$ In this regard, the main focus has been on how to improve the linkages and alignment between 'local' community-based mechanisms and the encompassing administrative and regulatory systems of the modern state. This interest has arisen most prominently in relation to international engagements with so-called fragile and conflict-affected states. The latter, which would include Solomon Islands, are characterised by the weakness of their formal institutions, constrained fiscal circumstances and, often, the social complexity and conspicuous level of normative pluralism found in many postcolonial settings. In such cases, external interveners are urged to extend their engagement beyond state actors to include, for example, 'traditional' and religious leaders, as integral to the larger statebuilding project. $^{6}$

2 We use inverted commas here to signal the problematic treatment of this term/category_and the concept of scale more broadly - in much of the hybridity literature, a critique that we develop in a later section of the chapter.

3 We also use inverted commas here to acknowledge the problematic usage of the notion 'traditional' in much of the literature, often misleadingly implying a category that is bounded, static and oppositional to 'modern'.

4 See, for example, Allen et al., Justice Delivered Locally; Dinnen and Haley, Evaluation of the Community Officer Project in Solomon Islands; Evans et al., 'The Hybrid Courts of Melanesia'.

5 See Luckham and Kirk, 'Security in Hybrid Political Contexts'; World Bank, World Development Report 2011.

6 Smits and Wright, Engagement with Non-state Actors in Fragile States. 
We certainly see merit in attempts to address particular problems—such as high rates of family and sexual violence or chronic levels of substance abuse-through engagement with these 'local' systems of authority and regulation in places like Solomon Islands and have made recommendations to this effect in our research on justice delivery in that country's rural provinces. $^{7}$ At the same time, we also share many of the concerns raised by critics of 'the local turn' in peacebuilding and development, ${ }^{8}$ including in respect of the uncritical embrace of more instrumentalised forms of hybridity—what we have dubbed 'designer hybridity' — as a novel and innovative approach by external interveners to institutional reform. In the grounded case study that follows we elaborate on some of these concerns and, in doing so, make a number of points that connect with the broader themes-history, power and scale- of the workshop which provided the genesis for this edited collection. ${ }^{9}$

In the first place, we note that attempts to create linkages between different social orders and institutional forms have a long history in Solomon Islands, including through the experience of the indirect administration introduced initially by British colonial authorities, and that this longer history has had a significant influence on contemporary efforts to promote hybridity. Second, we note that such attempts have by no means been confined to international or national-level actors seeking to instrumentalise top-down processes of domination or reform but are also apparent in the actions of local actors seeking to connect and negotiate with the latter. These local agendas for hybridity have also been profoundly shaped by longer histories of interaction with external actors and processes, as have the local social orders that are driving them.

Third, and as pointed out by many others, ${ }^{10}$ these interactions are invariably infused and mediated through existing power relations and contests, serving particular interests and neglecting or militating against others. Related to this, our fourth point draws attention to the scalar dimensions of these processes of hybridisation and the need to move beyond the crude scalar binaries (such as 'local-supranational' or 'localliberal') that have characterised much of the hybridity literature in order to adequately engage with the hierarchies of power that animate them.

\footnotetext{
7 See, for example, Allen et al., Justice Delivered Locally.

8 Björkdahl and Höglund, 'Precarious Peacebuilding'; Meagher, 'The Strength of Weak States?'; Peterson, 'A Conceptual Unpacking Of Hybridity'.

9 See the Introduction to this volume for more information.

10 For example, Nadarajah and Rampton, 'The Limits of Hybridity'.
} 
We acknowledge that some of our own work has been guilty on this count, although we have previously flagged scale as a problematic concept in the hybridity literature. ${ }^{11}$ What we are seeking to do here through emphasising the importance of scalar analysis is to draw attention not only to the subnational scales of social and political organisation that are frequently overlooked in the hybridity discourse, such as the scale of the island province in the case of Solomon Islands and other archipelagic territories, but also to the various ways in which power has been rescaled, and new scales produced, in the context of successive phases of political economic struggle.

The final point from our research in Solomon Islands, and one that we have made previously, ${ }^{12}$ questions the assumption in much of the existing literature that local-level actors have a natural preference for local forms of authority, organisation and regulation over those of state and transnational forms. Instead, we have found a strong desire among many of our Solomon Islander interlocutors for greater engagement with Weberian-like institutions that are perceived — whether rightly or wrongly — as being more emancipated from corrosive and corrupting dimensions of contemporary social and power relations. While neotraditional institutions such as those associated with chiefly authority continue to enjoy widespread legitimacy, the apparent demand for Weberian institutions, especially police and courts, is, in large part, based on a growing recognition among Solomon Islanders of the increasing frailty and politicisation of these 'local' institutions in the face of contemporary change. ${ }^{13}$

These five points can be distilled down to what we see as three critical limitations to the analytical value of hybridity as a lens with which to view the process of state formation; limitations, we suggest, that have resonance well beyond Solomon Islands. First, hybridity's crude approach to scale is blind to the vertical power dynamics that are becoming increasingly animated by globalised processes of political and economic change. Second, it is not only national and supranational actors that may attempt to instrumentalise hybridity; a raft of subnational actors may also engage with such agendas both discursively and materially. Third, it is wrong to assume that the 'local' is always synonymous with the 'non-state' or the 'traditional'. In elucidating these limitations with reference to our case study from Solomon Islands, we also demonstrate the indispensability

11 Dinnen and Allen, 'State Absence and State Formation in Solomon Islands'.

12 Ibid.

13 See Wallis, this volume. 
of attention to history and power relations to any robust analysis of state formation. In this sense, history and power relations provide crosscutting, or encompassing, themes for our reflection upon the limits of hybridity as an analytical lens on state formation.

The first section of our chapter introduces the Solomon Islands case study, paying particular attention to the historical and geographical complexities of state formation in this archipelagic and socially diverse postcolonial and postconflict nation-state. We also define what we mean by the politics of scale and map out the (hierarchically ordered) scales of political and social organisation that we suggest are essential to any adequate and historically grounded analysis of state formation in the Solomons context. We then turn to the three main arguments we introduced above, providing brief sections on hybridity and the politics of scale, 'local' agendas for instrumentalist hybridity, and agency and the growing 'local' demand for emancipated institutions. In our concluding section we suggest that the three limitations to hybridity that we elucidate are by no means terminal. On the contrary, we see much that is analytically useful in the concept of hybridity for understanding processes of state formation. Indeed, the data we draw upon in this brief reflection demonstrates the value of descriptive hybridity as a methodological tool in the tradition of grounded ethnographic research. By drawing attention to the three limitations expounded here it is our intention that future hybridity research and practice might explicitly engage with them, thereby enriching and advancing the hybridity project and its-albeit qualifiedutility as an analytical lens on state formation.

\section{Understanding the complexities of state formation in Solomon Islands}

These islands, lying 1,800 kilometres off Australia's north-east coast, possess the extraordinary ethnolinguistic diversity that is characteristic of Melanesia, with 80 languages spoken by a population of around 600,000 people. Rates of urbanisation are low, with most people living in rural hamlets and villages where contemporary forms of 'community' are based on complex interplays of kinship and exchange relations, 'traditional' and neo-'traditional' governance structures, friendships, membership of Christian churches and myriad claims to customary land of which 
genealogical descent is only one. Intense social diversity, geographical fragmentation and a widely dispersed population have long problematised the extension of centralised authority.

Commencing with colonisation by Great Britain, successive forces both external and internal have shaped the nature of the state and its interactions with society. These have included projects of pacification, missionisation, labour commodification, direct and indirect rule, institutional modernisation, globalised natural resource capitalism, patronage, structural adjustment and, most recently, a major liberal peacebuilding intervention in the form of the Australian-led Regional Assistance Mission to Solomon Islands (RAMSI). First deployed in 2003 and finally withdrawn in mid-2017, RAMSI came about largely in response to a period of violent internal conflict known locally as the 'ethnic tension'. The tension involved a complex interaction of historical factors, motivations and actors at different geographical scales and was, in fact, like many other recent conflicts, the manifestation of multiple local conflicts that mutated and escalated over time. ${ }^{14}$ However, for concerned Australian policymakers in the early 2000s, it was viewed primarily through the global lens of 'state failure' and the threat this ostensibly posed to Australian and regional security. ${ }^{15}$

While central government could be said to have effectively collapsed during the tension period, changing relations between the political centre and rural periphery since independence meant that the state was already widely perceived as absent from rural areas before the outbreak of the tension in $1998 .{ }^{16}$ However, while this narrative of state withdrawal is embraced by many rural Solomon Islanders it remains a contested one. Even if the state is interpreted primarily in terms of service delivery and development, ${ }^{17}$ the depiction of its uniform and linear retreat from rural regions demands qualification because there has, in fact, been an expansion of some government services, notably health and education, in the postcolonial period. Fourteen years of substantial investment by RAMSI has also seen improvements in this regard. Significantly, there are also compelling political economy grounds for contesting the statewithdrawal narrative. These relate to the exponential expansion of

14 Kalyvas, 'The Ontology of "Political Violence".

15 Fry and Kabutaulaka, 'Political Legitimacy and State-building Intervention in the Pacific'.

16 Herlihy, 'Always We Are Last'; McDougall, 'Sub-national Governance in Post-RAMSI Solomon Islands'.

17 Bierschenck and de Sardan, 'Studying the Dynamics of African Bureaucracies'. 
discretionary constituency development funds (known as CDFs) at the disposal of individual national members of parliament such that these now dwarf national grants to provincial governments.

For some observers, the latter development is indicative of a fundamental reordering of power that has taken place in Solomon Islands over the past few decades. ${ }^{18}$ However, this reordering could also be seen as a form of rescaling: the consolidation of power in the hands of national-level political elites. This has involved the progressive evisceration of the middle (provincial) and local levels of government. In the case of the former, the division of responsibilities between provincial and national tiers has always been unclear, while provincial administrations have been subjected to perennial underfunding from the political centre. ${ }^{19}$ The system of locallevel government was effectively dismantled when the former area councils were officially suspended in 1998 as a consequence of both domestically and internationally driven structural adjustment programs against the larger backdrop of the Asian financial crisis.

Building upon and, in many ways, exacerbating historical patterns of uneven development introduced initially under colonialism, globalised extractive resource capitalism, in the form of the logging industry and a more recent intensification in mining activity, has also been a powerful animator of rescaling and reordering. The nexus between the notoriously corrupt logging sector and the larger pattern of political patronage that has shaped political development in the post-independence period has been well documented. ${ }^{20}$ As has been the case in neighbouring Papua New Guinea, including in its Autonomous Region of Bougainville, the encounter with extractive resource capitalism has produced 'customary landownership' as a new and potent scale in both horizontal and vertical power struggles, especially over economic benefits, at the same time that it has animated the island province as scale for collective political action in benefit-sharing struggles. ${ }^{21}$

We suggest that despite its significant engagement over 14 years, RAMSI left many of these political economy dynamics alone and, in doing so, may have inadvertently served to reinforce and accentuate them by reifying

18 Craig and Porter, 'Political Settlement in Solomon Islands'.

19 Cox and Morrison, 'Solomon Islands Provincial Governance Information Paper'.

20 Bennett, Pacific Forest, Dauvergne, 'Corporate Power in the Forests of Solomon Islands'; Kabutaulaka, 'Rumble in the Jungle'.

21 Allen, 'Melanesia’s Violent Environments'; Filer, 'Compensation, Rent and Power in Papua New Guinea’. 
and reinforcing the national scale as the key locus of political power. In this sense RAMSI was, in effect, if not necessarily by design, aligned with a rescaling of power under CDFs that was already taking place before the intervention, a point that has been made by Hameiri. ${ }^{22}$ While it would be unfair to hold the regional mission responsible-its objectives were altogether more modest - the fact remains that this substantial liberal intervention did little to shift the existing political economy of natural resource extraction. It also left unchallenged the exclusionary and dysfunctional political settlement that provides the setting for continuing grievances, including many that contributed to the original conflict. In this respect, Craig and Porter have demonstrated how the clientelism that continues to characterise relations between Solomon Islands' political and economic elites has had a profoundly corrosive impact on policy processes and contributes to enduring instability. ${ }^{23}$

At this juncture it is necessary to define what we mean by 'the politics of scale'. Briefly, drawing upon work in political and economic geography, we see scale as socially produced and constantly reconfigured through sociopolitical struggle. ${ }^{24}$ Relationality and hierarchy are key defining characteristics of scale, though, importantly, these hierarchies can be reconfigured and scale, in this sense, is not fixed. Lastly, scalar politics are deployed regularly in political power struggles, both as 'tactics' by less powerful social groups and as 'strategies' by elites, to draw on Michel de Certeau's distinction. ${ }^{25}$ In the case of Solomon Islands, we see the following scales as pertinent to an analysis of the politics of scale:

- Very local. The village level and, even below that, the kinship group, clan or tribe.

- Regionallsub-island. For example, geographically circumscribed social movements such as the Christian Fellow Church in parts of Western Province. ${ }^{26}$ This scale might be conterminous with language boundaries and/or national constituencies.

22 Hameiri, 'Public Administration Reform and the Politics of Scale'.

23 Craig and Porter, 'Political Settlement in Solomon Islands'.

24 Brenner, 'The Limits to Scale?'; Smith, Uneven Development, 160-178; Swyngedouw, 'Neither Global nor Local'.

25 See Kent, this volume. For de Certeau, 'strategies' - typically employed by elites—usually involve official plans and defined frameworks for achieving desired goals, while 'tactics' are the more flexible approaches tailored to immediate contexts likely to be used by less powerful groups. De Certeau, The Practice of Everyday Life.

26 Hviding, 'Re-placing the State in the Western Solomon Islands'. 
- Provinciallisland. Most provinces (subnational jurisdictions) in Solomon Islands are geographically conterminous with a large island and the island province, due to its unique territorial qualities, is an especially potent, though problematic, scale for collective political action through the mobilisation of island-wide identities.

- National. The scale at which political power is being increasingly concentrated through the growth of CDFs and various forms of rent seeking.

- Supranational. This scale is critically important in the case of Solomon Islands because of the recent RAMSI intervention, the economic dominance of globalised extractive resource capitalism, and the legacies of earlier (colonial period) forms of intervention and statebuilding.

\section{Hybridity and the politics of scale}

Building upon an earlier article, ${ }^{27}$ we contrast our analysis of state formation against existing scholarship on Solomon Islands that has tended to privilege the ascription of agency at one particular scale: either the very local or sub-island (taking the form of detailed ethnographic analyses of particular communities or social movements) $;^{28}$ the national (such as the political settlement interpretations with a focus on national elites); ${ }^{29}$ or the supranational (in the form of analysis that sees supranational actors as the primary driver of change in Solomon Islands). ${ }^{30}$ Without detracting from the insights provided by these studies, our objective here is to bring an explicitly multi-scalar sensibility to bear on both processes of state formation and the analytical utility of hybridity for understanding them. This requires the facility to navigate between scales.

As mentioned in the introduction, much of the hybrid peace literature operates within a crude spatial ontology in which the 'local' appears as an extremely fuzzy and imprecise category that is primarily constructed in opposition to the supranational and/or the liberal. This clumsy scalar binary leads to much definitional slippage: in some instances the 'local' appears to refer to what we have identified above as the very local scale; in others it seems to refer to the national scale; and in yet others, it is taken

27 Dinnen and Allen, 'State Absence and State Formation in Solomon Islands'.

28 For example, Timmer, 'Kastom and Theocracy'.

29 For example, Craig and Porter, 'Political Settlement in Solomon Islands'.

30 For example, Hameiri, 'State Building or Crisis Management?'. 
to mean everything that is not supranational and/or liberal. Moreover, hybridity's scalar binary is also blind to the inherent dynamism of the politics of scale: it is unable to account for the reconfiguration of existing scales, and the production of new ones, that has occurred during different historical phases of political and economic struggle. Another aspect of the politics of this construction is how 'the local' is often represented in a manner that renders it as remote, marginal or 'marked by absence'. ${ }^{31}$ This construction can, in turn, have consequences in terms of the ways in which policymakers approach particular locations.

We have already noted that CDFs can be usefully interpreted as a rescaling of power and that the advent of extractive resource industries has produced customary landownership as a new scale of political economic contestation at the same time that it has animated benefit-sharing tensions between the national and provincial scales. We are reminded that Solomon Islands has a long history of these sorts of scalar dynamics. The introduction of capitalist social relations under colonialism, especially in the form of international and domestic plantation labour trades, and subsequent patterns of uneven capitalist penetration (in conjunction with colonial cartographies that territorialised large islands into subnational jurisdictions for the administrative convenience of colonial authorities) has produced and reproduced the island province as a potent scale in political economic power struggles.

These politics of scale have found expression in longstanding tensions and debates about political devolution and decentralisation, and were an important factor in the origins of the 'ethnic tension'. ${ }^{32}$ Set against the long haul of state formation, the tensions between national and subnational scales remain an important area of continuity as witnessed by an enduring agenda for constitutional change and the proposed adoption of a federal system of government that would see not only devolution of functions and powers subnationally, but also the formalisation of the many and varied subnational projects of instrumentalist hybridity that will be discussed below. The draft constitution contains significant scope for local accommodation, inflection and agency-provinces and 'community governments' will have considerable scope to do their own

31 See, for example, Gupta and Ferguson, Culture, Power, Place. We are grateful to a reviewer of our draft chapter for pointing this out and introducing us to the relevant literature.

32 The issue of centre-periphery relations (that is, between Honiara and the rest of the country) has been a critical fault line in Solomon Islands politics since decolonisation. See, for example, Larmour and Qalo, Decentralisation in the South Pacific. 
thing. ${ }^{33}$ Hybridity, in this sense, remains a useful lens for looking at these national/subnational tensions but only after its unsophisticated and defective approach to critical spatial/scalar dimensions has been remedied. Put bluntly, hybridity's crude scalar binary runs the risk of glossing over, or simply failing to see, critically important political contestation and dynamism between the national and multiple subnational scales that we have identified. Nor is hybridity alert to the production of new, previously unimaginable, scales of political economic struggle.

\section{'Local' agendas for instrumentalist hybridity}

This brings us to our second critique of the hybridity literature as it has been applied to the theory and practice of peace building and statebuilding. That is, the assumption that instrumentalist agendas for hybridity are the exclusive domain of actors at the supranational or national scales. The growing critique of instrumentalised or 'designer' hybridity in the critical peacebuilding literature is largely directed at the international actors involved in these interventions and questions the practicality, efficacy and ethics of such endeavours, including the high risks of unintended consequences. ${ }^{34}$ While the recent RAMSI mission was almost exclusively focused on building/rebuilding the central agencies of state (and rightly criticised for this narrow focus), our work in rural Solomon Islands indicates there are extensive efforts being directed towards forms of instrumentalised hybridity at the very local, sub-island and provincial scales_-particularly in areas of dispute resolution, policing and governance. What this research clearly demonstrates is that it is not only supranational actors that have been actively pursuing instrumentalist hybridity agendas.

A number of points have emerged in our analysis of these subnationally driven agendas for hybrid institutions. The first is the sheer range of subnational actors who are engaged in instrumentalised hybridity and the diverse forms that these innovative activities assume. ${ }^{35}$ They include extensive experimentation in informal governance arrangements at the very local level including a proliferation of village 'committees',

33 'Constitution of the Federated Democratic Republic of Solomon Islands', 2nd draft, 6 May 2014.

34 See, for example, Meagher, 'The Strength of Weak States?'; Peterson, 'A Conceptual Unpacking of Hybridity'.

35 Allen et al., Justice Delivered Locally, 69-78. 
'councils' and 'associations'. 'Traditional', predominantly male, leaders or 'chiefs' continue to have a prominent role in these local structures, but there is also evidence of participation by representatives of other groups, including women, youth and churches. Another manifestation lies in the proclamation of elaborate, often written, community 'rules', 'laws', 'by-laws', 'ordinances' and, in some cases, constitutions. Some of this activity may involve mimicry of state forms aimed at enhancing the visibility and legibility of local structures to actors at other scales such as governments and donors, ${ }^{36}$ with the hope of initiating productive relations with them. There is also a strong element of self-help and local problem solving that is largely substitutive in the absence of tangible and effective linkages to more encompassing administrative and service delivery systems.

Experimentation is also evident at the provincial scale, with a number of provinces actively exploring ways of improving downward linkages with structures at the most local levels. These have been influenced by the wider and longstanding debates about constitutional reform and federalism, as well as by pressure from rural communities for improved service delivery and local development opportunities. The hybrid character of these provincial initiatives is evident in deliberate attempts to integrate state, church and 'traditional' forms of authority into provincial or island-wide governance models, as with Isabel's well-known 'tripod' system. ${ }^{37}$ These locally and provincially driven efforts to reconfigure what are already hybridised governance arrangements also serve to blur the distinction between 'descriptive' and 'instrumentalised' hybridity that recurs in the broader literature. ${ }^{38}$

Following on from above is our observation that these contemporary examples of experimentation with hybrid governance at local and provincial levels have themselves been profoundly shaped by a much longer colonial and postcolonial history of hybridisation across different institutional forms, value systems and types of social ordering. ${ }^{39}$ The clearest historical example of instrumentalised hybridity was the introduction of 'indirect rule' by the British colonial authorities, working through 'chiefs', 'headmen' and various local intermediaries, as well as

36 McDougall, 'Customary Authority and State Withdrawal in Solomon Islands'.

37 Baines, 'Beneath the State'.

38 Millar, 'Disaggregating Hybridity'.

39 McDougall, 'Customary Authority and State Withdrawal in Solomon Islands'. 
through the establishment of 'native courts' to administer 'customary law'. Syncretism between 'introduced' Christianity and local normative systems is evident in the long history of missionisation. Christianity, kastom and state forms have also been interwoven in the social movements that have appeared throughout Solomon Islands modern history, often as explicit alternatives to the social and political ordering of the colonial and postcolonial state. These movements, including Maasina Rule in Malaita, ${ }^{40}$ the Moro Movement in Guadalcanal ${ }^{41}$ and, more recently, the Christian Fellowship in parts of Western Province, ${ }^{42}$ represented an early form of re-territorialisation and deployed kastom as an ideology of resistance. The Western 'breakaway' movement during decolonisation and, as noted in our rural research, the current phenomena of 'colonial nostalgia' and 'state withdrawal' similarly serve to highlight the historical and hybrid aspects of political contestation within and between different scalar levels. ${ }^{43}$

The critical question, as we see it, is not so much about the instrumentalisation of hybridity per se, as it is about the actors and interests promoting these agendas and, specifically, who stands to benefit - and who stands to lose-from their advocacy and realisation. In short, analytical focus should be upon the power relations that animate the pursuit and shape the outcomes of these instrumentalised approaches to hybridity and the manner in which they play out at different scales. In the case of Solomon Islands, this remains an important priority for continuing and future research.

\section{Agency and the growing 'local' demand for emancipated institutions}

In our earlier article ${ }^{44}$ we were critical of some aspects of the 'local turn' literature, notably for the assumption that the local level would automatically privilege 'local' over 'national' or 'supranational' forms (an assumption that has, in turn, generated a critique of 'the

40 Akin, Colonialism, Maasina Rule, and the Origins of Malaitan Kastom.

41 Davenport and Çoker, 'The Moro Movement of Guadalcanal'.

42 Hviding, 'Re-placing the State in the Western Solomon Islands'.

43 Allen et al., Justice Delivered Locally.

44 Dinnen and Allen, 'State Absence and State Formation in Solomon Islands'. 
romanticisation of the local'). ${ }^{45}$ The more complex picture that emerged from the research we reported in that paper was the desire at all subnational scales for statebuilding with a strong local inflection and degree of local autonomy, on one hand, and a strong desire for aspects of Weberian or liberal statehood, particularly in relation to the management of newer forms of conflict stresses, on the other. Rather than being mutually exclusive, these simultaneous demands for local autonomy and an explicit acknowledgement of a particular role for certain institutions of liberal statehood indicated a strong desire for more effective articulation between local and state regulatory systems that would enhance the effectiveness of both, as well as the alignment between them.

The views expressed by rural villagers recognised the increasing frailties of local institutions and structures in the face of contemporary globalisation and, in particular, the socially disintegrative and frequently violent effects of resource extraction. The attraction of certain aspects of Weberian or liberal statehood at local levels was expressed in the preference for RAMSI (that is, international) police over the Royal Solomon Islands Police Force, in the desire for local non-state actors to be backed by the 'shadow of the law', as well as in the mimicry of state forms intended to attract external recognition and engagement, and in the widespread nostalgia for an older system of indirect rule that was believed to have effectively connected the legitimacy of local leaders with the functional authority of the state. As in other cases of 'colonial nostalgia', the underlying sentiment rests more on discontent with the ethnographic present than with any real desire to return to the colonial past. ${ }^{46}$ While the historical veracity on which this nostalgia is based is certainly open to question, it reflects a contemporary situation where local elites or 'chiefs', as well as many police units operating in rural areas, are all too often deeply compromised in the current political economy through their entanglements with logging and other commercial extractive operations. This situation again highlights the significance of the underlying power relations informing the configuration and outcomes of hybrid forms of regulation in practice.

Another dimension of the frequently encountered nostalgia for the colonial system of indirect rule is the perception that colonial institutions, such as that of the district officer, were impartial and effectively impervious to potentially corrupting social relations, especially those that drove,

45 Richmond, 'De-romanticising the Local, De-mystifying the International'.

46 Bissell, 'Engaging Colonial Nostalgia'. 
and continue to drive, loyalty to one's own kinship or language group (commonly expressed in contemporary parlance as wantokism). Our research demonstrates that RAMSI police are seen in a similar light: they are perceived as being immune from the social and political economic relations that can imperil the partiality of local police. ${ }^{47}$ In this manner, we once again see the importance of history in informing and framing contemporary discourses around regulation and institutional development more broadly. Moreover, despite the growing recognition among rural Solomon Islanders of the frailties of their local institutions, such as those associated with 'chiefs', these institutions continue to enjoy a significant degree of legitimacy as reflected in widespread calls to empower 'chiefs' and link them into formal governance and law and order structures.

\section{Conclusion}

This brief reflection on the analytical utility of the concept of hybridity as a lens on state formation has drawn upon a case study of Solomon Islands to highlight three deficiencies with the concept: its clumsy and problematic treatment of scale, its tendency to see projects of instrumental hybridity as the exclusive purview of national and supranational actors, and its assumption that 'local' actors will automatically privilege the 'traditional' over the 'liberal'. In concluding, we suggest that if these deficiencies are explicitly recognised and addressed, hybridity remains a useful lens, among others, to bring to bear upon processes of state formation. This point is perhaps best illustrated with reference to the politics of scale. Other contributors to this volume have suggested that hybridity be dispensed with entirely in favour of a scalar understanding of institutional change in the context of political and economic contestation. ${ }^{48}$ However, our view is that this would simply substitute one form of methodological and theoretical, and perhaps ontological, privileging with another.

We are very sympathetic to the proposition that new scales are produced, and existing scales reconfigured, in the course of political economic struggle. Indeed we have argued that the politics of scale is a salient lacuna in the literature on hybridity and statebuilding and peacebuilding. However, we have also demonstrated in the case of Solomon Islands that these

47 Dinnen and Allen, 'Paradoxes of Postcolonial Police-Building'.

48 See Hameiri and Jones, this volume. 
scalar dynamics have critical social and cultural inflections. This applies, for example, to the emergence of customary landownership as a scale in the contentious politics of extractive resource industries, to the types of institutions that have emerged at the scale of the island province, and even to the rescaling of power that has occurred with the advent and rapid growth of CDFs. In this sense neither scale nor hybridity are, on their own, sufficient to achieve interpretive and analytical rigour. In concert, however, these lenses may start to provide a more robust perspective on state formation, even more so when the other limitations to hybridity that we have highlighted —especially its problematic treatment of agencyare explicitly addressed. And, of course, with agency comes questions of structure, contingency, history and power relations. In the final analysis, then, all of these things matter if we are to develop solid understandings of processes of state formation in highly complex postcolonial and postconflict settings. Hybridity, in this sense, is not a panacea. 
This text is taken from Hybridity on the Ground in Peacebuilding and Development: Critical Conversations, edited by Joanne Wallis, Lia Kent, Miranda Forsyth, Sinclair Dinnen and Srinjoy Bose, published 2018 by ANU Press, The Australian National University, Canberra, Australia.

doi.org/10.22459/HGPD.03.2018.08 